\title{
Efeitos a longo prazo da aplicação de adesivos cirúrgicos na perviedade de tubas uterinas de coelhas
}

Long-term effects of the application of surgical adhesives on the patency of the uterine tubes of rabbits

Autor: Henri Chaplin Rivoire

Orientador: Prof. Dr. Djalma José Fagundes

Tese apresentada para obtenção do título de Doutor na Universidade Federal de São Paulo - Escola Paulista de Medicina - Programa de Pós-Graduação em Cirurgia e Experimentação, em 17 de agosto de 2006.

Objetivo: estudar aspectos morfométricos e perviedade tubária em coelhas, submetidas à obstrução, transvaginal, com adesivos de fibrina, GRF ou cianoacrilato. Métodos: 57 coelhas ( $n=114$ tubas uterinas), New Zealand, férteis, foram randomizadas em quatro grupos. Grupo I ( $n=24$ tubas) foi o Grupo Simulado no qual só foi realizado cateterismo tubário; Grupo II ( $\mathrm{n}=30$ tubas) recebeu 0,25 $\mathrm{mL}$ de adesivo de fibrina em cada tuba; Grupo III ( $\mathrm{n}=30$ tubas) recebeu $0,25 \mathrm{~mL}$ de adesivo de GRF; Grupo IV ( $n=30$ tubas) teve a colocação de 0,25 $\mathrm{mL}$ de adesivo de $\mathrm{n}$-butil-2-cianoacrilato. Cada grupo foi redistribuído para observação por 30, 90 e 180 dias, à direita e à esquerda. As coelhas foram acasaladas duas vezes por semana com machos com fertilidade comprovada. Foi avaliado o peso e as gestações, e após a eutanásia foram analisados: cavidade abdominal para detectar falhas técnicas, perviedade tubária in vitro (Teste de Pressão de Rompimento até $40 \mathrm{mmHg}$ ), morfometria do diâmetro tubário $(\mathrm{cm})$, da mucosa e do miosalpinge $(\mathrm{mm})$, densidade óptica total da mucosa e processo inflamatório. A análise estatística comparou os lados direito e esquerdo qualitativamente pelo Teste de McNemar e quantitativamente pela Prova de Wilcoxon; os subgrupos de tempo e os grupos foram avaliados qualitativamente pela Generalização do Teste Exato de Fischer e quantitativamente pela Prova de Kruskal-Wallis, e as diferenças foram localizadas pelo teste de comparações múltiplas de Dunn. O nivel de significância adotado foi de 0,05 ( $a \leq 5 \%)$ e valores significantes assinalados por asterisco. Resultados: Não houve falhas técnicas detectáveis. Todas as tubas dos Grupos I e II estavam pérvias nos tempos do estudo, o que não ocorreu com as tubas dos Grupos III e IV. Ocorreu gestação em todos os animais do Grupo I e em $83,3 \%$ do Grupo II (exceto em cinco úteros em 30 dias no Grupo II) e não houve gestação em nenhum elemento dos Grupos III e IV. A análise dos pesos mostrou variação significante no Grupo III, em que todos os animais apresentaram peso final $(3.550 \pm 550 \mathrm{~g}) \mathrm{me}-$ nor que o peso inicial $(4.05 \pm 850 \mathrm{~g})$, em decorrência da toxicidade do adesivo de GRF. A morfometria mostrou aumento significativo da mucosa (médias de 0,300,43-0,44 $\mathrm{mm}$ aos 30-90-180 dias respectivamente) e do miosalpinge (médias de 0,44-0,72-0,85 $\mathrm{mm}$ aos 30-90-180 dias respectivamente) das tubas do Grupo IV que foi relacionado a tentativa de expulsar o adesivo sintético. A densidade óptica total da mucosa mostrou aumento significativo no Grupo III, no subgrupo de 180 dias com média de 0,31 , enquanto nos subgrupos de 30 e 90 dias, a média foi de 0,30 e 0,28 respectivamente, em virtude da hiperplasia celular desencadeada pela ação lesiva do adesivo de GRF. O processo inflamatório mostrou cronicidade no Grupo III com 180 dias $40 \%$ de inflamação leve, $50 \%$ de inflamação moderada e $10 \%$ de inflamação acentuada). Conclusões: o adesivo de fibrina não obstruiu as tubas, foi absorvido e não produziu alterações morfológicas nas tubas. O adesivo de GRF obstruiu as tubas, foi absorvido e produziu alterações morfológicas importantes na mucosa e miosalpinge das tubas. O adesivo de n-butil-2-cianoacrilato obstruiu as tubas impedindo a gestação, não foi absorvido e não provocou alterações qualitativas relevantes na mucosa das tubas uterinas, embora tenha alterado as espessuras da mucosa e miosalpinge.

PALAVRAS-CHAVE: Tubas uterinas; Esterilização reprodutiva; Coelhas; Cirurgia experimental; Adesivos cirúrgicos 